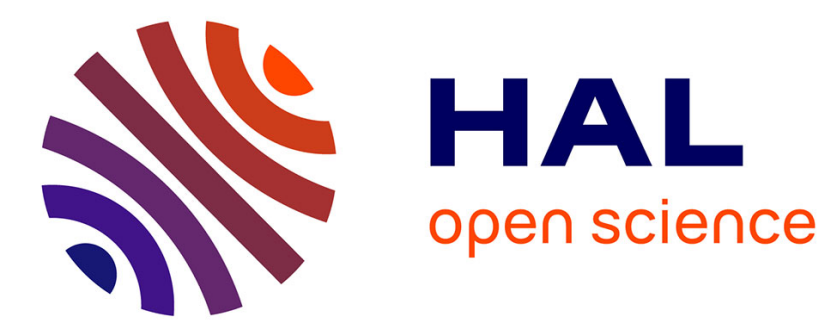

\title{
New Insights of the Solid State Transformations in the Ag-Se-Ge System : a Mechanical Spectroscopy Study
}

\author{
S. Etienne, G. Taillades, A. Pradel, M. Ribes
}

\section{To cite this version:}

S. Etienne, G. Taillades, A. Pradel, M. Ribes. New Insights of the Solid State Transformations in the Ag-Se-Ge System : a Mechanical Spectroscopy Study. Journal de Physique IV Proceedings, 1996, 06 (C8), pp.C8-655-C8-658. 10.1051/jp4:19968141 • jpa-00254574

\section{HAL Id: jpa-00254574 https://hal.science/jpa-00254574}

Submitted on 1 Jan 1996

HAL is a multi-disciplinary open access archive for the deposit and dissemination of scientific research documents, whether they are published or not. The documents may come from teaching and research institutions in France or abroad, or from public or private research centers.
L'archive ouverte pluridisciplinaire HAL, est destinée au dépôt et à la diffusion de documents scientifiques de niveau recherche, publiés ou non, émanant des établissements d'enseignement et de recherche français ou étrangers, des laboratoires publics ou privés. 


\title{
New Insights of the Solid State Transformations in the Ag-Se-Ge System: a Mechanical Spectroscopy Study
}

\author{
S. Etienne, G. Taillades*, A. Pradel* and M. Ribes* \\ LMPSM, UA 155 du CNRS, Ecole des Mines, Parc de Saurupt, 54042 Nancy cedex, France \\ * LPMC, UMR 5617 du CNRS, Université Montpellier II, Place E. Bataillon, 34000 Montpellier cedex, \\ France
}

\begin{abstract}
Summary: a study of degrees of freedom exhibited by partially crystallised material of the system Ag-Se-Ge is reported. Mechanical spectroscopy reveals 3 processes in the temperature range $250 \mathrm{~K}$ to $330 \mathrm{~K}$. Two processes at $298 \mathrm{~K}$ and $315 \mathrm{~K}$ are assigned to solid statc transformations in $\mathrm{Ag}_{8} \mathrm{GeSe}_{6}$ crystallites. A broad relaxation process exhibiting a high activation energy is connected to cooperative events assumed to occur in the glassy matrix. The two first processes also manifest in DSC cxpcriments. The high temperature one is definitively attributed to allotropic transformation of $\mathrm{Ag}_{8} \mathrm{GeSe}_{6}$ crystalline phase. The low temperature one is reported for the first time in this paper and is attributed to the transformation of a crystalline metastable phase induced by constraints imposed by the surrounding glassy matrix.
\end{abstract}

\section{INTRODUCTION}

A study of glassy chalcogenide material of composition $0.2 \mathrm{Ag}_{2} \mathrm{Se}, 0.8 \mathrm{GeSe}_{3}$ has been previously reported $[1,2]$. It was shown that this material exhibits two relaxation processes: a so called $\beta$ or sub $\mathrm{Tg}$ relaxation attributed to localised atomic motions and a main relaxation presenting cooperative features connected to the glass transition. In addition, a low temperature relaxation process was observed near 125K (frequency $1 \mathrm{~Hz}$ ) induced by the thermomechanically activated jumps of $\mathrm{Ag}^{+}$ions, in agreement with electrical conductivity measurements. A glass containing a slightly higher amount of $\mathrm{Ag}_{2} \mathrm{Se}\left(0.25 \mathrm{Ag}_{2} \mathrm{Se}, 0.75 \mathrm{GeSe}_{3}\right)$ and presenting partial crystallisation is studied in this paper. The effect of this crystallisation on the different degrees of freedom as sudied by means of mechanical spectroscopy is reported. Additional data are provided by calorimetry and electrical measurements.

\section{EXPERIMENTAL PROCEDURE}

\subsection{Material and specimen preparation}

The appropriate amount of reacting materials were introduced in a silica ampoule which was evacuated up to $10^{-4}$ torr, sealed and placed in a rocking furnace. The product was heated at $900^{\circ} \mathrm{C}$ to obtain a homogeneous liquid and then allowed to cool down to room temperature. The ingot was cut in platelets of dimensions $40 \times 6 \times 0.7 \mathrm{~mm}^{3}$ and $6 \times 6 \times 0.7 \mathrm{~mm}^{3}$ for mechanical spectroscopy and electrical conductivity measurements respectively and polished.

In addition, a batch of pure $\mathrm{Ag}_{8} \mathrm{GeSe}_{6}$ was prepared according to ref [3]. Electrical conductivity measurements were carried out on a pellet of $10 \mathrm{~mm}$ in diameter and $1 \mathrm{~mm}$ thick.

\subsection{Experimental Techniques}

WAXS patterns were taken at room temperature with a Rigaku diffractometer ( $\mathrm{Cu} \mathrm{K} \alpha$ radiation) equipped with a $\theta / 2 \theta$ goniometer.

Calorimetry characterisation were carried out with a DSC 200 Netzsch. The heating rate was $10 \mathrm{~K} / \mathrm{min}$. 
Electrical conducticity $\sigma_{D C}$ was assessed via impedance spectroscopy by extrapolation down to zero frequency. The setup consisted of a General Radio model 1693 impedance meter and a cell allowing measurements in the range $220 \mathrm{~K}-400 \mathrm{~K}$ under vacuum. The electrical contacts were platinum deposited electrodes.

The dynamic mechanical modulus $G^{*}(j \omega)=G^{\prime}(\omega)+j G^{\prime \prime}(\omega)=G(\omega) \exp j \varphi(\omega)$ was measured by means of a low frequency spectrometer previously described [4] working in the temperature/frequency range $90 \mathrm{~K}$ $500 \mathrm{~K} / 10^{-4}-10 \mathrm{~Hz}$. The strain amplitude did not exceed $10^{-5}$.

\section{RESULTS}

\subsection{Characterisation by WAXS}

WAXS pattern shows diffraction lines characteristic of the crystalline $\mathrm{Ag}_{8} \mathrm{GeSe}_{6}$ phase. These sharp lines are superimposed on the broad diffraction halo of the glassy $\mathrm{GeSe}_{3}$ rich matrix.

\subsection{Mechanical Spectroscopy Results}

Figure 1 shows results of low frequency mechanical spectroscopy. The isochronal curves (figure 1a) clearly displays 3 relaxation processes in the temperature range $250 \mathrm{~K}-350 \mathrm{~K}$. The two processes occuring at $298 \mathrm{~K}$ and $315 \mathrm{~K}$ manifest as sharp peaks associated with a modulus anomaly. The shoulder near $200 \mathrm{~K}$ is identified as the $\beta$ relaxation[1]. The temperature and intensity of the broad peak that develops in the range $250 \mathrm{~K}-330 \mathrm{~K}$ are sensitive to the measurement frequency, in contrast with the previous ones. The evolution of the broad peak is presented in more details in isothermal regime (figure 1b).
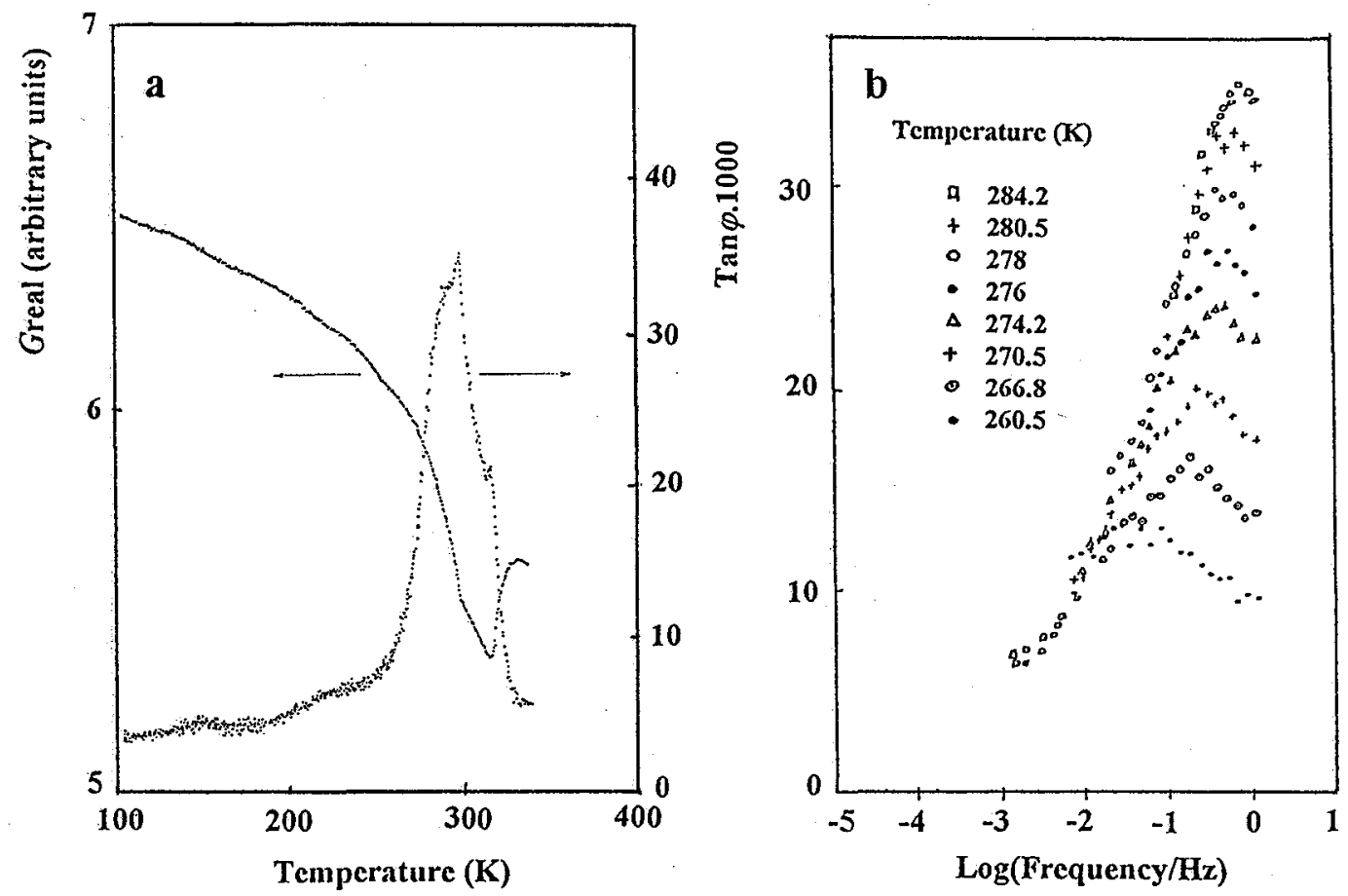

Figure 1: Dynamic behavior measured by low frequency mechanical spectroscopy:

a) isochronal mode and b) isothermal mode (only $\tan \varphi$ is represented) 
It is to be underlined that the low temperature relaxation peak attributed to the jumps of $\mathrm{Ag}^{+}$ions in the glassy matrix has almost vanished.

\subsection{Calorimetry study}

Calorimetry experiments are carried out in the temperature range $250 \mathrm{~K}-573 \mathrm{~K}$. The glass transition of the glassy matrix is thus determined equal $470 \mathrm{~K}$ according to the onset of the endotherm. As shown in figure 2 , several thermal effects are observed in the range $250 \mathrm{~K}-350 \mathrm{~K}$ : four endothermic peaks develop at $278 \mathrm{~K}$, $299 \mathrm{~K}, 320 \mathrm{~K}$ and $345 \mathrm{~K}$. A shoulder is also present on the low temperature tail of the $320 \mathrm{~K}$ peak.

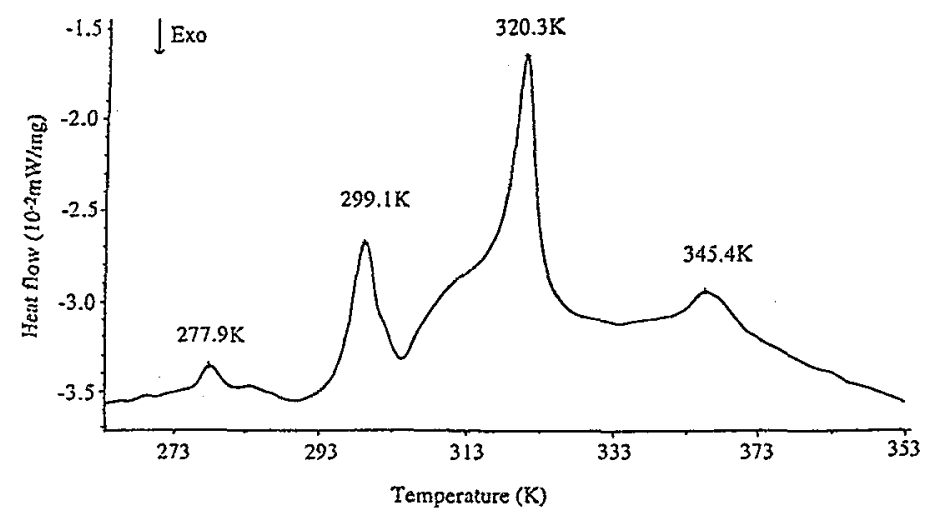

Figure 2: Calorimetry scan $(10 \mathrm{~K} / \mathrm{min})$. Only the part under interest $250 \mathrm{~K}-350 \mathrm{~K}$ is represented.

\subsection{Electrical Conductivity}

The complex impedance plots clearly show two semicircles indicating an electrical inhomogeneity of the

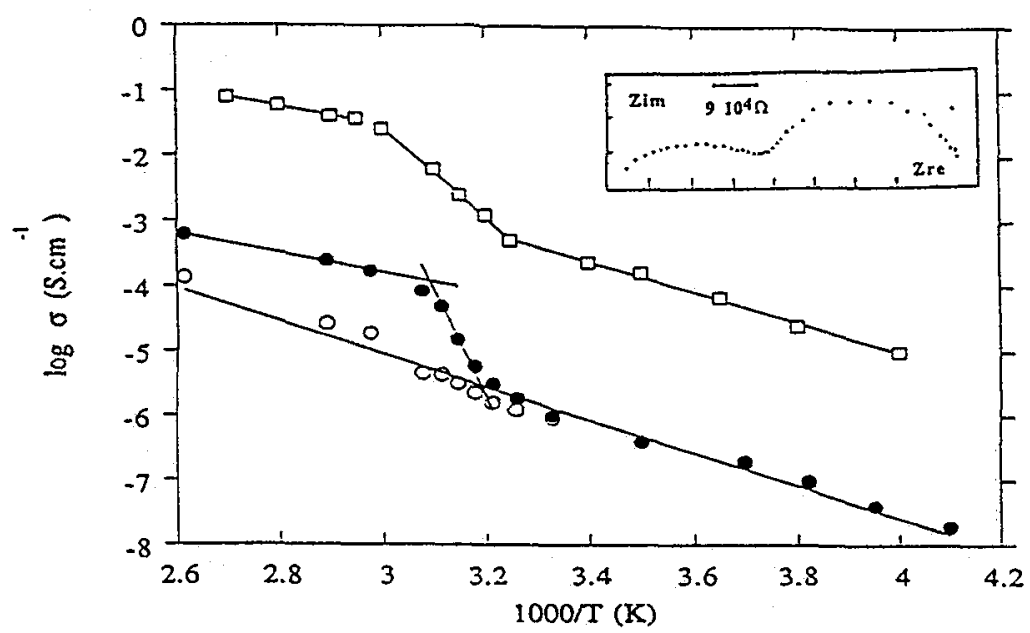

Figure 3: Arrhenius plot of pure $\mathrm{Ag}_{8} \mathrm{GeSe}_{6}(\square)$ and of the phases present in $0.25 \mathrm{Ag}_{2} \mathrm{Se}_{0} 0.75 \mathrm{GeSe}_{3}$ (low frequency $(O)$ and high frequency $(\bullet)$ semicircles). The Cole Cole plot at $303 \mathrm{~K}$ is shown in the inset. 
material and therefore the presence of at least two phases (inset in figure 3). The two semicircles can be independently analysed. Their temperature dependence is reported in figure 3 together with that of the pure $\mathrm{Ag}_{8} \mathrm{GeSe}_{6}$ crystalline compound. The dc conductivity deduced from the high semicircle shows a jump of about two orders of magnitude at a temperature of about $320 \mathrm{~K}$ close to that observed on the pure $\mathrm{Ag}_{8} \mathrm{GeSe}_{6}$ conductivity curve. Moreover the activation energies of the low and high temperature conductivities are similar for both materials i.e. 0.51 and $0.3 \mathrm{eV}$ for the partially crystallised material respectively and 0.45 and $0.33 \mathrm{eV}$ for $\mathrm{Ag}_{8} \mathrm{GeSe}_{6}$. On the other hand the dc conductivity deduced from the low frequency semicircle obeys an Arrhenius law with an activation energy of $0.51 \mathrm{eV}$ in the whole investigated temperature range. The conductivities of the phases present in the examined material are similar at low temperature.

\section{DISCUSSION AND CONCLUSION}

Mechanical spectroscopy, electrical conductivity and DSC measurements show that the partial crystallisation of $0.25 \mathrm{Ag}_{2} \mathrm{Se}, 0.75 \mathrm{GeSe}_{3}$ proceeds in a complex way. The presence of the crystalline phase is obvious (lines in the Xray diffraction pattern, endothemic peaks at $278 \mathrm{~K}$ and $321 \mathrm{~K}$ on the DSC curve corresponding to the successive allotropic transformations $\alpha^{\prime} \rightarrow \beta^{\prime} \rightarrow \gamma$ of $\mathrm{Ag}_{8} \mathrm{GeSe}_{6}$ phase [3], jump in the conductivity curve at about $320 \mathrm{~K}$ very similar to that observed for the pure $\mathrm{Ag}_{8} \mathrm{GeSe}_{6}$ conductivity $\left(\beta^{\prime} \rightarrow \gamma\right)$, sharp peak indicating a phase transition at the same temperature on the isochronal $\tan \varphi$ curve). Other features show that one or more additional phases are present. For example, if the high temperature endotherm at $345 \mathrm{~K}$ has already been reported by Gorochov in the DTA curve of pure $\mathrm{Ag}_{8} \mathrm{GeSe}_{6}$ even though it was not identified, the additional peak at $299 \mathrm{~K}$ on the DSC curve has never been reported. It is assigned to a second crystalline phase which undergoes a transition at this temperature. This fact is supported by the $\operatorname{sharp} \tan \varphi$ maximum with the temperature peak unsensitive to frequency which is observed at the same temperature by mechanical spectroscopy. The presence of the low frequency semicircle on Cole Cole impedance plots and the high values of the conductivity deduced from this semicircle indicate that a second conductive phase is present.

As a result a non negligeable amount of silver is not incorporated in the $\mathrm{Ag}_{8} \mathrm{GeSe}_{6}$ crystallites. Whether it is present in the glassy matrix or in the second crystalline phase cannot be deduced from conductivity measurements. The mechanism responsible for the broad $\tan \varphi$ peak observed on isochronals (figure 1a) is more difficult to identify. Frequency scans (figure $1 b$ ) show that it is a relaxation process, but with a strong departure from Arrhenius behaviour (high apparent activation energy and strength sensitive to temperature). It could be assigned to the nanocomposite structure i.e. constraints of amorphous matrix on crystallites of different chemical compositions with misfit of thermal expansion. These observations reveal the behavior complexity of the material resulting from $0.25 \mathrm{Ag}_{2} \mathrm{Se}, 0.75 \mathrm{GeSe}_{3}$ partial crystallisation and illustrate the interest of complementary techniques. Further experiments are in progress in order to better clarify this behavior.

\section{References}

[1] Etienne S., Perez J., Peytavin S. and Ribes M., J. Solid State Chem., 92 (1991) 27-38

[2] Etienne S., Pradel A. and Ribes M., J. Non-Cryst. Solids, 131-133 (1991) 1072-1075

[3] Gorochov O., Bull. Soc. Chim. France, 6 (1968) 2263-2275

[4] Etienne S., "Low frequency: Special Techniques", in Mechanical Spectroscopy in Materials Science, Magalas L.B. Ed., (Chapman and Hall, London, in press). 